\title{
High Performance DC-to-AC Converter Using Snubberless H- Bridge Power Switches and an Improved DC-to-DC Converter
}

\author{
Candidus U. Eya ${ }^{1}$, Ayodeji Olalekan Salau ${ }^{2}$, Stephen Ejiofor Oti ${ }^{3}$ \\ ${ }^{1,3}$ Department of Electrical Engineering, University of Nigeria, Nsukka, Nigeria \\ ${ }^{2}$ Department of Electrical/Electronics and Computer Engineering, Afe Babalola University, \\ Ado Ekiti, Nigeria
}

Received: August 20, 2020. Revised: March 9, 2021. Accepted: April 6, 2021. Published: April 8, 2021.

Abstract: This paper presents the analysis, modeling, simulation, and implementation of a high performance DC-to-AC (DC-AC) converter. The system comprises of a combination of DC power source, stress less DC-to-DC (DC-DC) voltage converter, two snubberless power switches, and control unit. The system is portable, has a two-stage input voltage transformation and amplification with no transformer and occupies less space unlike the classical twostage inverter systems. In addition, the system produces a constant DC boosted voltage with less stress on both the source and DC storage capacitor which are not found in conventional converters. The proposed power electronic converter system produced the following results: pure sine voltage and current waveforms, total

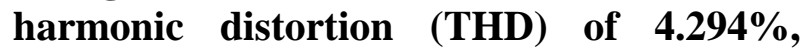
power output of $5740 \mathrm{~W}$, efficiency of $98.9 \%$, power loss of $60 \mathrm{~W}$ and fast dynamic response. The target areas of applications of the proposed converter are in medium and small scale industries.

Keywords: DC-DC converter, high performance, snubberless, converter,

\section{INTRODUCTION}

High performance of DC-to-AC (DC-AC) converters convert DC power to $\mathrm{AC}$ power at desired output voltages, currents, and frequencies [1]. The conversion of DC power to $\mathrm{AC}$ power is not imaginary but is real for power electronic components. In recent times, the demand for power electronic converters has increased mainly due to industrialization and the quest to provide an alternative power supply to remote parts of the globe because of the lack of constant power supply in most developing countries [2]. The DC-AC power converter has numerous applications ranging from lightening of bulbs in our different respective homes, used in driver motors for small and medium scale industries, uninterruptible power supply in telecommunication industries, farm storage systems, biomedical laboratories, etc. These converters exist in various forms such as single phase, three phase, five phase, and six phase inverters; single stage, double stage, and multistage inverters; two level, three level and multilevel inverters; transformer-based and transformer-less inverters; voltage and current source inverters and many other classifications [3-7].

Typically in a single stage inverter, the inversion is performed by one stage conversion. It has merit of low power circuit cost and high conversion efficiency. However, they have enormous complex control methods (double loop feedback scheme, quad-loop feedback systems, and so on), high switching losses, elevated control component counts, 
large input voltage level due to low transformation ratio, high load transiency, and complicated control computations. Based on these challenges in single stage inverter, the overall efficiency or performances of these inverters are reduced which also leads to increase in control conduction losses of the power switches [8-10]. In addition, they experience a reverse recovery problem in antiparallel diodes. On the other hand, multilevel inverters have low harmonics distortions and high power handling capabilities but are expensive due to their large number of components [11-15]. Similarly, the two-stage DC-to-AC power converter is another interesting type of inverter. This is because it is mostly used when the source voltage is low whereas AC applications require high voltages due to their high transformation ratio. Some typical examples are incorporated in Fuel cells, solar panels, super capacitors, rectified output voltage from wind power, etc. Two- stage DC-AC power converters are placed between the source voltage and $\mathrm{AC}$ power loads to avoid using power transformers and its associated problems as observed in conventional inverters in raising an output voltage. There are numerous two-stage power inverters which have been proposed by a number of researchers [16-23]. Some classical examples are shown in Fig. 1 [16-19] and Fig. 2 [20-23]. The two-stage power inverters in Figs. 1 and 2 suffer from huge stray capacitances and inductances; electromagnetic interferences, large space, power losses, high voltage stresses on both source supply and capacitors, and are expensive due to the inclusion of snubber circuits during practical implementation.

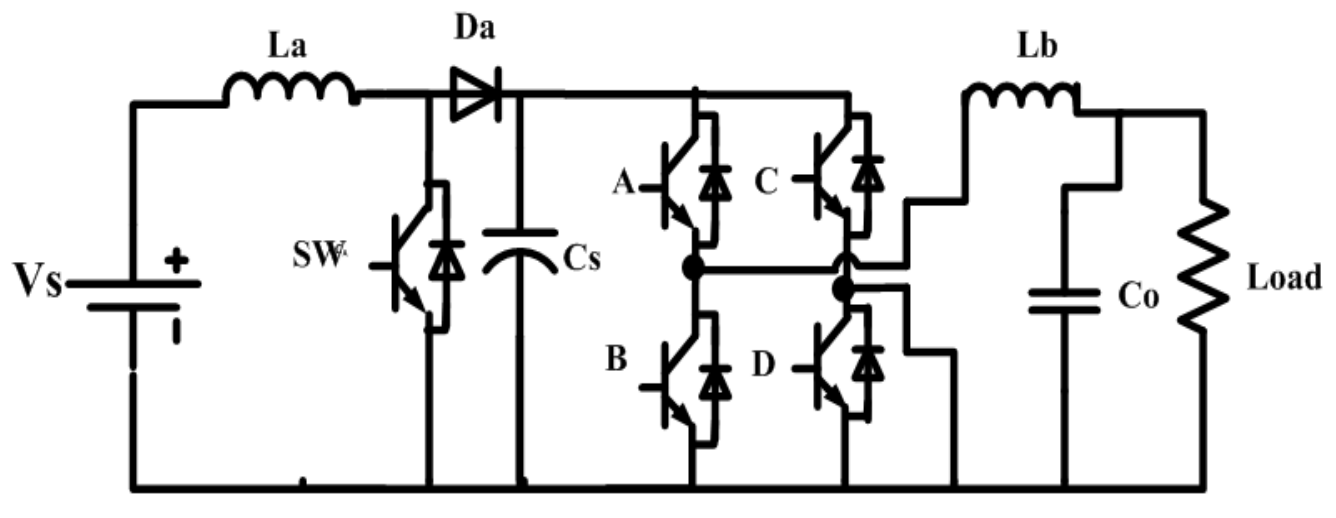

Fig. 1. Two-stage boost DC-AC converter.

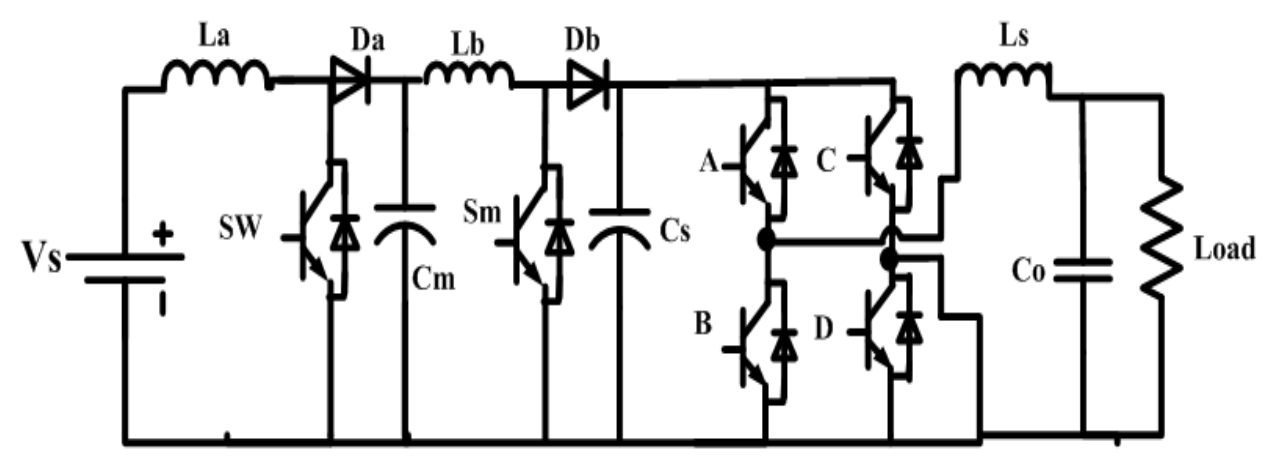


Fig. 2. Cascaded two-stage DC-AC power converter.

In this paper, we evaluate the performance of a two-stage DC-to-AC power converter with snubberless $\mathrm{H}$-bridge power switches and less stressful DC-to-DC (DC-DC) converter. The identified research problems which are addressed in this paper are: (i) issue of stray capacitances and inductances that occur in $\mathrm{H}$ bridge inverters due to the use of two separate switches on each leg of the H-bridge inverter of a classical two-stage inverter system, (ii) inclusion of a snubber circuit in $\mathrm{H}$-bridge inverters due to excess voltage during the off period in a classical two-stage inverter system, (iii) voltage stresses that occur on storage and filtering capacitors when DC-DC power switches are ON which leave the load to depend completely on the capacitors, (iv) Time consumed and cost when two separate power switches are joined on each leg of a $\mathrm{H}-$ bridge inverter during practical experimentation, (v) large space and size of heat sink of the two separate switches of each leg of a H-bridge of an inverter. With the resolution of the stated challenges, the efficiency of the proposed system will increase and power losses will be minimized, hence increasing the performance and the reliability of the proposed system.

The H-bridge power switch used in this research work is IXYSFII 40-06D (IXYS ISOPLUS FII 40-06D). IXYSFII 40-06D has two inbuilt power switches with five pinouts per one leg of H-bridge inverter unlike the classical H-bridge inverter with six pinouts where the two power switches are separated. During the practical implementation, the cost and time of soldering the two switches are eliminated unlike when building the conventional H-bridge inverters. Secondly, the issues of stray capacitance, electromagnetic interference and inductance which are common in the classical H-bridge inverters are highly minimized. Thirdly, the large space and power losses are also mitigated due to the nature of the power switches used in the $\mathrm{H}$ bridge inverter. This inverter does not need snubber circuit. This is because during its turnoff period, its freewheeling diode (HiPerfred diode) has the capability of handling up to $18000 \mathrm{~W}$ at a temperature of $25^{\circ} \mathrm{C}$ and $9000 \mathrm{~W}$ at a temperature of $90^{\circ} \mathrm{C} \mathrm{[24].} \mathrm{Moreover,} \mathrm{the}$ improved DC-DC power converter proposed ensures that during conduction, the voltage source and the capacitor storage share the stress unlike in the traditional two-stage DCAC power converter where the capacitors are meant to bear the whole stress when the power diodes are in OFF state or the voltage source completely takes up the whole stress during the ON state of the power switch. Furthermore, because of the nature and type of stress shared between the source and the capacitor during conduction, the DC-DC converter uses the advantage to supply constant boosted DC voltage at the input rail of the inverter. The circuit diagram of the proposed system is shown in Fig. 3. It is made of power voltage source (Vs), two IGBTs, two IXYSFII 40-06D (represented by M1 and M2), and a load. In the proposed system, the lower harmonics orders are reduced with the aid of pulse-with modulation schemes such as DCtriangular based scheme and sinusoidal pulsewidth modulation. 


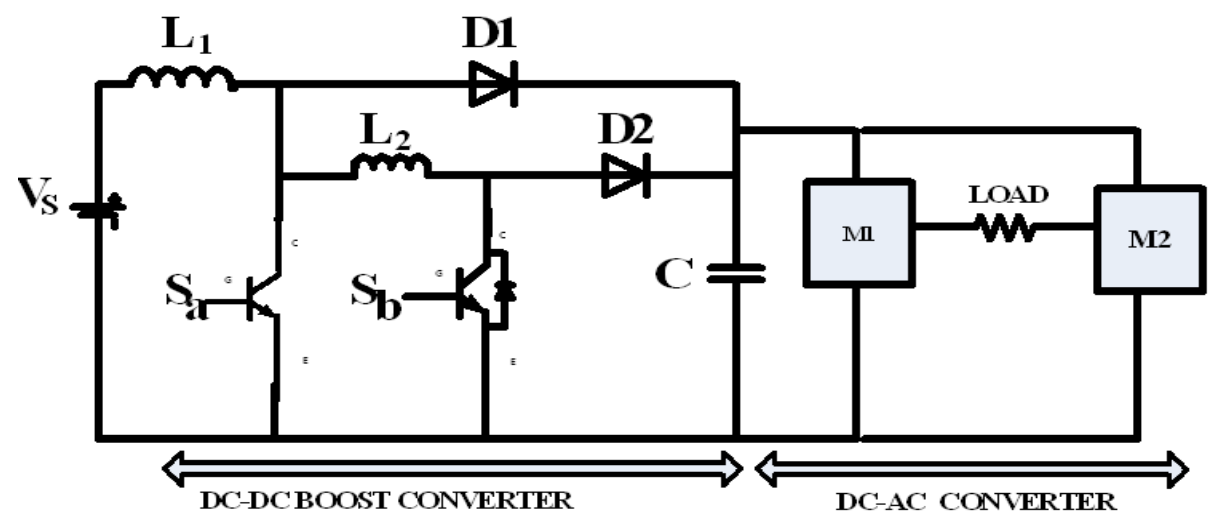

Fig. 3. Proposed DC-to-AC converter.

\section{ANALYSIS AND OPERATIONAL PRINCIPLES OF THE PROPOSED SYSTEM}

The proposed system operates in two modes (Mode 1 and Mode 2). In Mode 1, the low level voltage is converted to high level voltage (boosted voltage, $\mathrm{V}_{\mathrm{b} 1}$ ) and the output is placed at the input inverter rail, whereas in Mode 2, the boosted voltage is inverted to AC voltage at the operating frequency of the reference voltage.

(A) Mode 1: Mode 1 is further classified into two subsections. During the first subsection operation of this stage, the IGBT without anti-parallel diode, $\mathrm{S}_{\mathrm{a}}$ and power diode, $\mathbf{D}_{2}$ are turned $\mathrm{ON}$ and forward biased, whereas the IGBT with anti-parallel diode, $\mathrm{S}_{\mathrm{b}}$ and power diode, $\mathbf{D}_{1}$ are switched OFF and reverse biased. At this point, the current flows from the source to place the boosted voltage, $\mathrm{V}_{\mathbf{b}}$ across the inverter input terminals. The paths of the current flow are: $\mathbf{V}_{\mathbf{s}} \rightarrow \mathbf{L}_{\mathbf{1}} \rightarrow \mathbf{L}_{\mathbf{2}} \rightarrow$ $\mathbf{D}_{\mathbf{2}} \rightarrow \mathbf{C} \rightarrow \mathbf{V}_{\mathbf{s}}$ to build magnetic energy linearly in $\mathbf{L}_{1}$, plus $\mathbf{L}_{\mathbf{2}} \rightarrow \mathbf{D}_{\mathbf{2}} \rightarrow \mathbf{C} \rightarrow \mathbf{V}_{\mathbf{s}}$ to charge the capacitor, and $\mathbf{L}_{2} \rightarrow \mathbf{D}_{2} \rightarrow Z_{\text {inv }} \rightarrow$ $\mathrm{V}_{\mathrm{s}}$ to place the boosted voltage at the input inverter terminals. The circuit configuration is shown in Fig. 4. In Mode 1, three loops are created with three loop currents designated as $\mathbf{I}_{1}, \mathbf{I}_{2}$, and $\mathbf{I}_{3}$ as shown in Fig. 4.

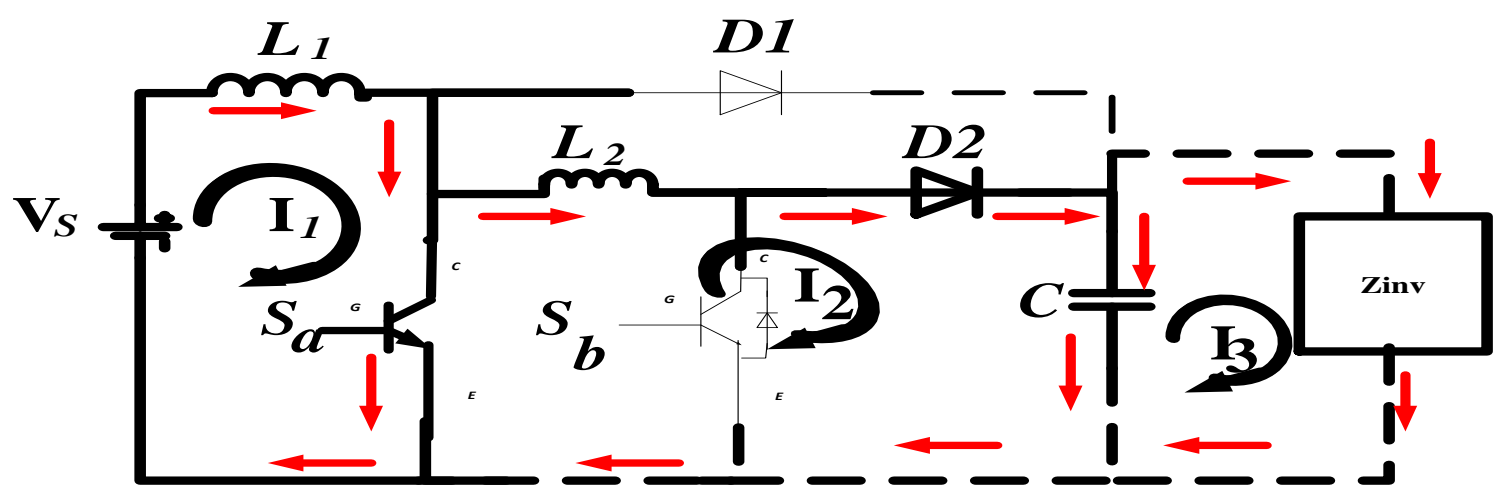

Fig. 4. Circuit configuration of the first subsection of Mode 1 of the proposed system. 
The relationship between the source voltage, $\mathbf{V}_{\mathbf{s}}$, impedances of the inductances of the inductors, $\mathbf{Z}_{\mathbf{L} 1}, \mathbf{Z}_{\mathbf{L} 2}$, capacitance of the capacitor $\mathbf{Z}_{\mathbf{C}}$, and the impedance of the inverter $\mathbf{Z}_{\mathbf{i n v}}$, neglecting the impedance of power diode, $\mathbf{Z}_{\mathbf{D} \mathbf{1}}$ are expressed in Eq. (1).

$$
\begin{gathered}
{\left[\begin{array}{l}
V_{s} \\
0 \\
0
\end{array}\right]=} \\
{\left[\begin{array}{c}
I_{1} \\
I_{2} \\
I_{3}
\end{array}\right]\left[\begin{array}{ccc}
Z_{L 1}+Z_{s a} & -Z_{s a} & 0 \\
-Z_{s a} & Z_{s a}+Z_{L 2}+Z_{c} & -Z_{c} \\
0 & -Z_{C} & Z_{C}+Z_{\text {inv }}
\end{array}\right]}
\end{gathered}
$$

The loop currents $\mathbf{I}_{1}, \mathbf{I}_{2}$ and $\mathbf{I}_{3}$ flowing in Fig. 4 are given by Eqs. (2)-(4).

$I_{1}=\frac{V_{S}\left[\left(Z_{s a}+Z_{L 2}+Z_{C}\right)\left(Z_{C}+Z_{i n v}\right)-Z_{C}{ }^{2}\right.}{\left[Z_{L 1}+Z_{s a}\right]\left[Z_{s a} Z_{C}+Z_{s a} Z_{i n v}+Z_{L 2} Z_{C}+Z_{L 2} Z_{i n v}+Z_{C}{ }^{2}+Z_{C} Z_{i n v}\right)-Z_{C}{ }^{2}+Z_{s a}{ }^{2}\left(Z_{C}+Z_{i n v}\right)}$

$I_{2}=\frac{V_{S}\left[Z_{s a}\left(Z_{C}+Z_{\text {inv }}\right)\right]}{\left[Z_{L 1}+Z_{s a}\right]\left[Z_{s a} Z_{C}+Z_{s a} Z_{i n v}+Z_{L 2} Z_{C}+Z_{L 2} Z_{\text {inv }}+Z_{C}{ }^{2}+Z_{C} Z_{\text {inv }}\right)-Z_{C}{ }^{2}+Z_{s a}{ }^{2}\left(Z_{C}+Z_{\text {inv }}\right)}$

$I_{3}=\frac{V_{S} Z_{s a} Z_{C}}{\left[Z_{L 1}+Z_{s a}\right]\left[Z_{s a} Z_{C}+Z_{s a} Z_{i n v}+Z_{L 2} Z_{C}+Z_{L 2} Z_{\text {inv }}+Z_{C}{ }^{2}+Z_{C} Z_{\text {inv }}\right)-Z_{C}{ }^{2}+Z_{s a}{ }^{2}\left(Z_{C}+Z_{\text {inv }}\right)}$

Then, the boosted voltage, $\mathrm{V}_{\mathrm{b} 1}$ after the first subsection of Mode 1 is given by Eq. (5).

$$
\mathrm{V}_{\mathrm{b} 1}=\mathrm{I}_{3} \mathrm{Z}_{\mathrm{inv}}
$$

During the second subsection operation of mode $1, \mathbf{S}_{\mathbf{b}}$ is switched $\mathrm{ON}$ and the power diode, D1 is forward biased, while $\mathbf{S}_{\mathbf{a}}$ and the power diode $\mathrm{D}_{2}$ are turned $\mathrm{OFF}$ and reverse biased. This causes the current flow from the source to place the boosted voltage, Vb1, across the inverter input terminals. Therefore, the paths of the current flow are: $\mathbf{V}_{\mathbf{s}} \rightarrow \mathbf{L}_{\mathbf{1}} \rightarrow$ $\mathbf{L}_{\mathbf{2}} \rightarrow \mathbf{S}_{\mathbf{b}} \rightarrow \mathbf{V}_{\mathbf{s}}$ to build magnetic energies linearly in $\mathbf{L} \mathbf{1}$ and $\mathbf{L} 2$, and $\mathbf{L}_{\mathbf{1}} \rightarrow \mathbf{D}_{\mathbf{1}} \rightarrow \mathbf{C} \rightarrow \mathbf{V}_{\mathbf{s}}$ to charge the capacitor, and $\mathbf{L}_{\mathbf{1}} \rightarrow \mathbf{D}_{\mathbf{1}} \rightarrow$ $\mathbf{Z}_{\text {inv }} \rightarrow \mathbf{V}_{\mathbf{s}}$ to place the boosted voltage, $\mathbf{V}_{\mathbf{b} 2}$ at inverter input terminals. The proposed circuit configuration is shown in Fig. 6. The second subsection of Mode 1 gives another set of three loop currents, $\mathbf{I}_{4}, \mathbf{I}_{5}$, and $\mathbf{I}_{6}$ as shown in Fig. 5.

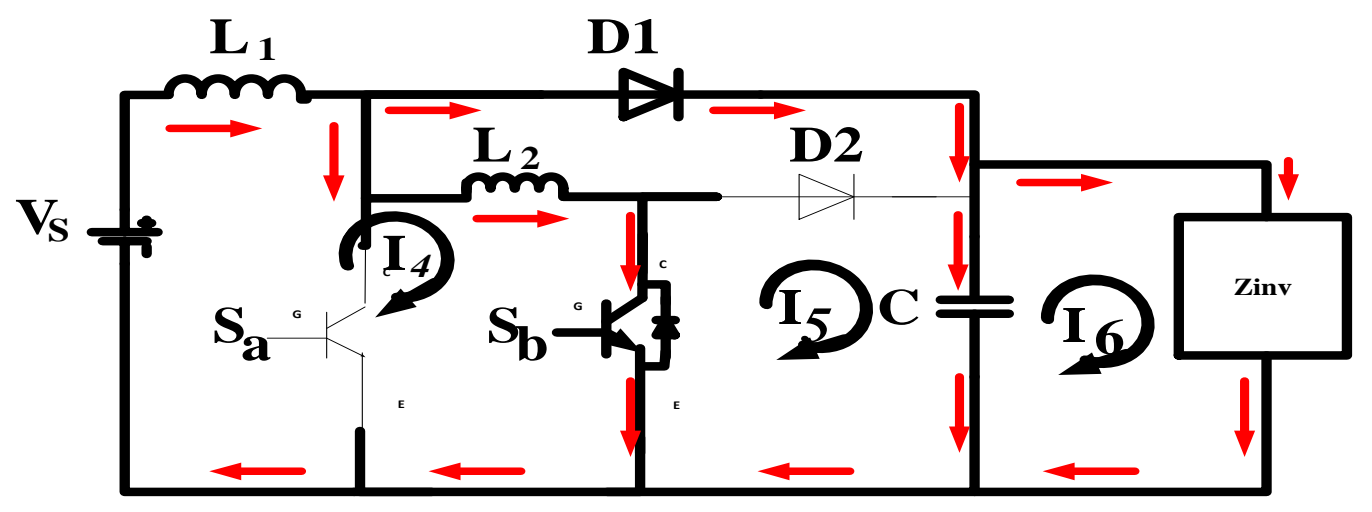

Fig. 5. Circuit configuration of second subsection of Mode 1 of the proposed system. 
The supply voltage, $\mathrm{Vs}$, and loop currents, $I_{4}$, $I_{5}$ and $I_{6}$ are related with impedances $Z_{L 1}, Z_{L 2}$, $Z_{s b}, Z_{C}, Z_{\text {inv }}$ of $\mathrm{L}_{1}, \mathrm{~L}_{2}, \mathrm{~S}_{\mathrm{b}}, \mathrm{C}$ of the inverter using the Eq. (6).

$$
\begin{aligned}
& {\left[\begin{array}{l}
V_{s} \\
0 \\
0
\end{array}\right]=} \\
& {\left[\begin{array}{l}
I_{4} \\
I_{6} \\
I_{7}
\end{array}\right]\left[\begin{array}{ccc}
Z_{L 1}+Z_{s b} & -Z_{L 1}-Z_{s b} & 0 \\
-Z_{L 1}-Z_{s b} & Z_{C}+Z_{L 2}+Z_{s b} & -Z_{C} \\
0 & -Z_{C} & Z_{C}+Z_{i n v}
\end{array}\right]}
\end{aligned}
$$

The loop currents $\mathbf{I}_{4}, \mathbf{I}_{5}$, and $\mathbf{I}_{\mathbf{6}}$ flowing in Fig. 5 are given by Eqs. (7)-(9).

$$
\begin{aligned}
& I_{4}=\frac{V_{S}\left[\left(Z_{s b}+Z_{L 2}+Z_{C}\right)\left(Z_{C}+Z_{i n v}\right)-Z_{C}{ }^{2}\right.}{\left[Z_{L 1}+Z_{L 2}+Z_{s b}\right]\left[-Z_{C}{ }^{2}-Z_{C} Z_{i n v}+Z_{L 2} Z_{C}+Z_{L 2} Z_{i n v}+Z_{C}{ }^{2}+Z_{C} Z_{i n v}+Z_{s b} Z_{i n v}\right)-Z_{C}{ }^{2}} \\
& I_{5}=\frac{V_{S}\left[\left(Z_{S b}+Z_{L 2}\right)\left(Z_{C}+Z_{i n v}\right)\right.}{\left[Z_{L 1}+Z_{L 2}+Z_{s b}\right]\left[-Z_{C}{ }^{2}-Z_{C} Z_{i n v}+Z_{L 2} Z_{C}+Z_{L 2} Z_{i n v}+Z_{C}{ }^{2}+Z_{C} Z_{i n v}+Z_{S b} Z_{i n v}\right)-Z_{C}{ }^{2}} \\
& I_{6}=\frac{V_{S} Z_{s b}+Z_{L 2}}{\left[Z_{L 1}+Z_{L 2}+Z_{s b}\right]\left[-Z_{C}{ }^{2}-Z_{C} Z_{i n v}+Z_{L 2} Z_{C}+Z_{L 2} Z_{i n v}+Z_{C}{ }^{2}+Z_{C} Z_{i n v}+Z_{S b} Z_{i n v}\right)-Z_{C}{ }^{2}}
\end{aligned}
$$

Therefore the boosted voltage, $\mathrm{V}_{\mathrm{b} 2}$ after the second subsection of Mode 1 is given by Eq. (10).

$$
\mathrm{V}_{\mathrm{b} 2}=\mathrm{I}_{6} \mathrm{Z}_{\mathrm{inv}}
$$

Also, when $V_{b 1}$ of Eq. (5) is equal to $V_{b 2}$ of Eq. (10), then the boosted voltage is

$$
\mathrm{V}_{\mathrm{b}}=\mathrm{V}_{\mathrm{b} 1}=\mathrm{V}_{\mathrm{b} 2}
$$

This shows that the constant boosted voltage is established across the inverter input terminals when either $S_{a}$ or $S_{b}$ is in the ON state. Moreover under the operation of Mode 1 , the relationship between boosted voltage and the duty cycle, D can be deduced using Eq. (12).

$$
\mathrm{V}_{\mathrm{b}=} \frac{2 \mathrm{~V}_{\mathrm{S}} \mathrm{D}+\mathrm{V}_{\mathrm{S}}+\mathrm{V}_{\mathrm{L} 1}}{1-2 \mathrm{D}}
$$

Eq. (12) shows that in generation of boosted voltage, no matter which switch is turned $\mathrm{ON}$, the voltage across $\mathrm{L}_{1}$ must be added. Therefore, the minimum inductance is given by Eq. (13).

$$
\mathrm{L}_{\text {min }}=\frac{\mathrm{V}_{\mathrm{S}} \mathrm{I}_{\mathrm{S}} \mathrm{Z}_{\mathrm{inv}}[1-2 \mathrm{D}]^{2}-\mathrm{DT}\left[\mathrm{V}_{\mathrm{S}}+\mathrm{V}_{\mathrm{L} 1}+\mathrm{V}_{\mathrm{b}}\right]}{2 \mathrm{~V}_{\mathrm{S}} \mathrm{D}+\mathrm{V}_{\mathrm{S}}}
$$

where $\mathrm{T}=1 / \mathrm{f}$ is the switching period,

To turn either $\mathrm{S}_{\mathrm{a}}$ or $\mathrm{S}_{\mathrm{b}} \mathrm{ON}$, the Eqs. (14) and (15) are compared to generate the switching pulses.

$$
\begin{aligned}
& \left.t_{r 1}=\llbracket \begin{array}{lll}
0 & \frac{1}{2 f_{c}} & \frac{1}{f_{c}} \\
0 & A_{r} & 0
\end{array}\right] \\
& \mathrm{d}_{\mathrm{c}}=A_{d} \mathrm{e}^{0}
\end{aligned}
$$

where $t_{r 1}, f_{c}, A_{r}, \mathrm{~d}_{\mathrm{c}}$, and $A_{d}$ represent triangular wave, switching frequency of carrier wave, amplitude of triangular wave, dc modulating signal, and amplitude of the dc modulating signal. Over-modulation occurrence is avoided in switching $\mathrm{S}_{\mathrm{a}}$ and $\mathrm{S}_{\mathrm{b}}$ provided that $A_{d}<A_{r}$. 
(B) Mode 2: In Mode 2, $\mathrm{V}_{\mathrm{b} 1}$ is converted to $\mathrm{AC}$ voltage when the direct current passes through the inversion regions of M1 (IXYSFII 40-06D) and M2 (IXYSFII 40-06D) of the Hbridge converter. M1 represents one leg of the H-bridge (half-bridge), while M2 represents the second leg of the inverter. M1 consists of two IGBT switches serially stacked together to form one module switch but functions by complementing each other. It has five pinout terminals. At the time of converting the boosted voltage to $\mathrm{AC}$ voltage, the power switches on each leg of the H-bridge should not be turned at the same time. The switching signals for the power switches M1 and M2 are obtained by comparing the sine wave and phase shifted sine wave reference signals of Eqs. (16) and (17) with the triangular wave of Eq. (18).

$$
\begin{aligned}
& S_{1 . r e f=} A_{a} \sin \theta \\
& S_{2 . r e f=} A_{a} \sin (\theta-180) \\
& C_{r 1}=\llbracket\left[\begin{array}{llll}
0 & \frac{1}{2 f} & \frac{3}{4 f} & \frac{1}{f} \\
0 & A_{c} & 0 & -A_{c}
\end{array} \rrbracket\right.
\end{aligned}
$$

The expression for converting the DC boost voltage to $\mathrm{AC}$ voltage $\mathrm{v}_{\mathrm{ac}}$ is given by Eq. (19) [24].

$$
\mathrm{v}_{\mathrm{ac}}=m_{a} \mathrm{~V}_{\mathrm{b}} \cos \left(\theta_{\mathrm{i}}-\frac{\pi}{2}\right)
$$

where $m_{a}$ and $\theta_{\mathrm{i}}$ are the amplitude modulation and phase of the two-stage single phase DC-to-AC converter. The efficiency, $\varepsilon$ of the two-stage boost DC-AC converter in this research work is computed using Eq. (20).

$$
\varepsilon=\frac{\text { output power } \times 100}{\text { Input power }}
$$

\section{MODELING OF THE PROPOSED SYSTEM}

The proposed system is modeled in MatLab/Simulink 2018 environment. The parameters used for the modeling are presented in the Table. 1.

Table. 1. Modeling Parameters.

\begin{tabular}{|c|c|}
\hline $\begin{array}{c}\text { Type of inverter } \\
\text { used }\end{array}$ & $\begin{array}{c}\text { Single phase two- } \\
\text { stage boost DC-AC } \\
\text { converter } \\
\text { parameters }\end{array}$ \\
\hline $\begin{array}{c}\text { Input voltage and } \\
\text { boosted voltage }\end{array}$ & $\begin{array}{c}48 \mathrm{~V} \text { DC and } \\
450 \mathrm{~V} \text { DC }\end{array}$ \\
\hline DC input power & $5800 \mathrm{~W}(5.8 \mathrm{~kW})$ \\
\hline $\begin{array}{c}\text { Switching } \\
\text { frequencies of } \\
\text { carriers }\end{array}$ & $\begin{array}{c}2.50 \mathrm{kHz} \text { and } \\
1.07 \mathrm{kHz}\end{array}$ \\
\hline $\begin{array}{c}\text { AC output } \\
\text { voltage (rms) }\end{array}$ & $338.9 \mathrm{~V}$ \\
& $(240 \mathrm{Vrms})$ \\
\hline $\begin{array}{c}\text { Inverter output } \\
\text { power }\end{array}$ & $5740 \mathrm{~W}(5.74 \mathrm{~kW})$ \\
\hline $\begin{array}{c}\text { L1 = L2 of DC- } \\
\text { DC circuit }\end{array}$ & $6.88 \mathrm{mH}$ \\
\hline DC-DC capacitor & $1200 \mu \mathrm{F}$ \\
\hline $\begin{array}{c}\text { Load resistance, } \\
\text { inductance and } \\
\text { capacitance }\end{array}$ & $45 \Omega, 5.5 \mathrm{mH}$ and \\
\hline $\begin{array}{c}\text { Proportional and } \\
\text { integral values }\end{array}$ & $50 \mu \mathrm{F}$ \\
\hline $\begin{array}{c}\text { Total harmonics } \\
\text { distortion (THD) }\end{array}$ & 1.01 and 0.57 \\
\hline Efficiency & $4.294 \%$ \\
\hline
\end{tabular}


The designed MatLab/Simulink block of the proposed system is shown in Fig. 6. The system was modeled in R2018a environment. It consists of the power supply, DC-DC power circuit converter, DC-AC power converter, feedback system, measuring instrument, total harmonics distortion (THD) measuring devices, and power GUI. It was observed from the THD display unit that the proposed system achieved $4.294 \%$ THD.

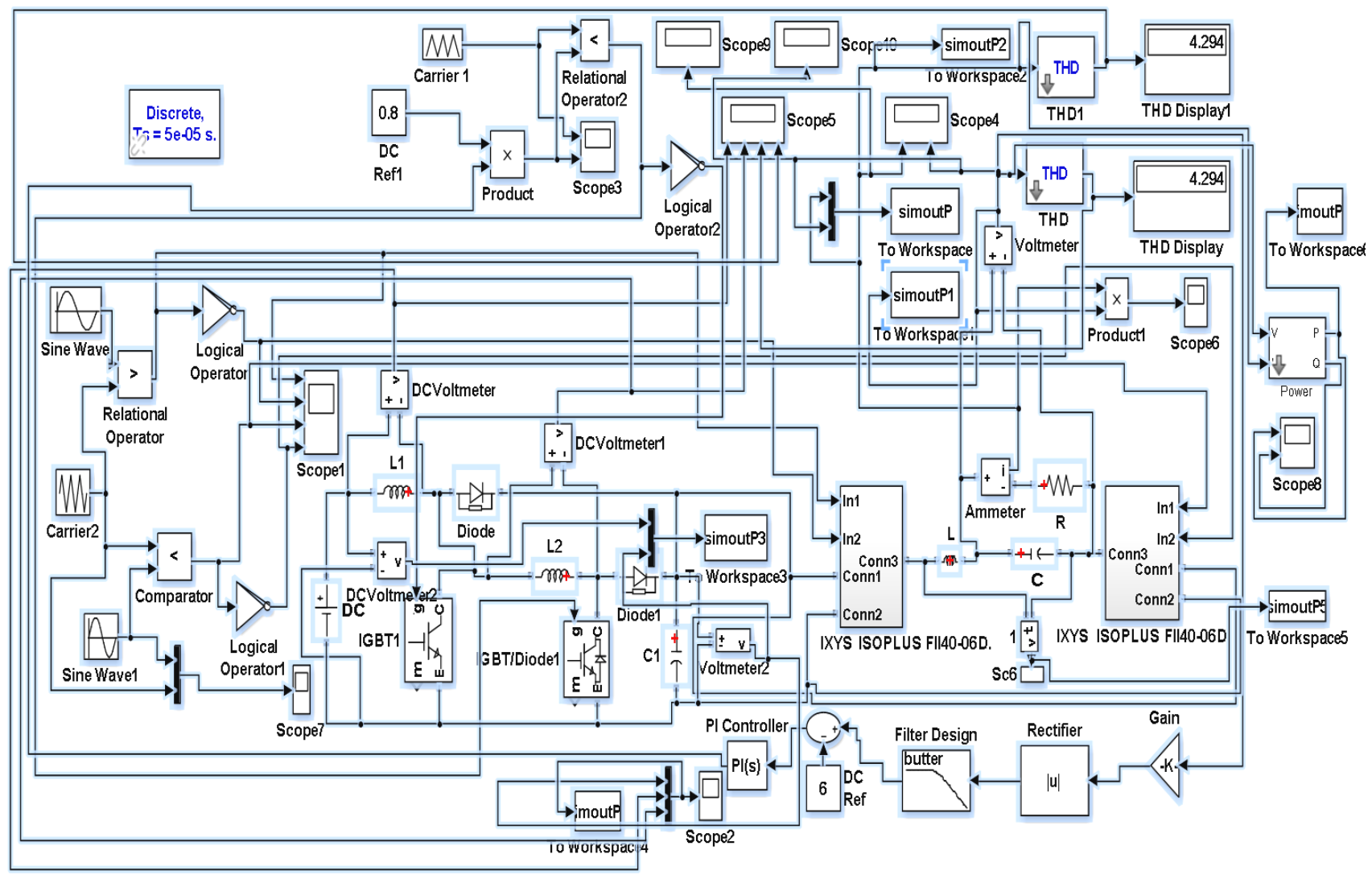

Fig. 6. MatLab/Simulink model of the proposed system. 
IV. RESULTS AND DISCUSSION OF SIMULATIONS AND EXPERIMENTATION OF THE PROPOSED SYSTEM

\section{(A) RESULTS AND DISCUSSION OF PROPOSED SIMULATIONS MATLAB/SIMULINK}

The source DC voltage and the results of the boosted voltage are shown in Fig. 7. The results indicate that the DC supply voltage is $48 \mathrm{VDC}$ and at $0<t<0.05 \mathrm{~s}$, the voltage supplied to the inverter terminal transiently increased from zero voltage until it is stabilized at $450 \mathrm{VDC}$ at $0.05<t \leq 1 s$ which is the boosted constant voltage supplied to the input terminals of the inverter.

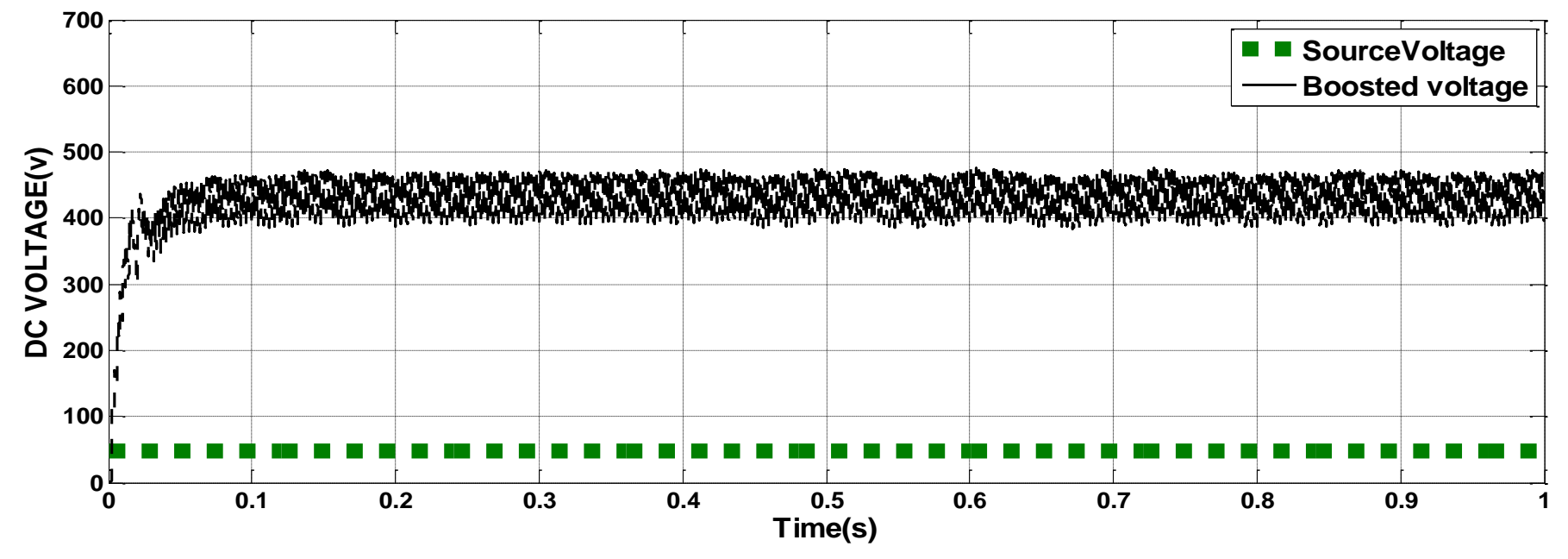

Fig. 7. Source DC voltage and DC-DC boosted voltage versus time.

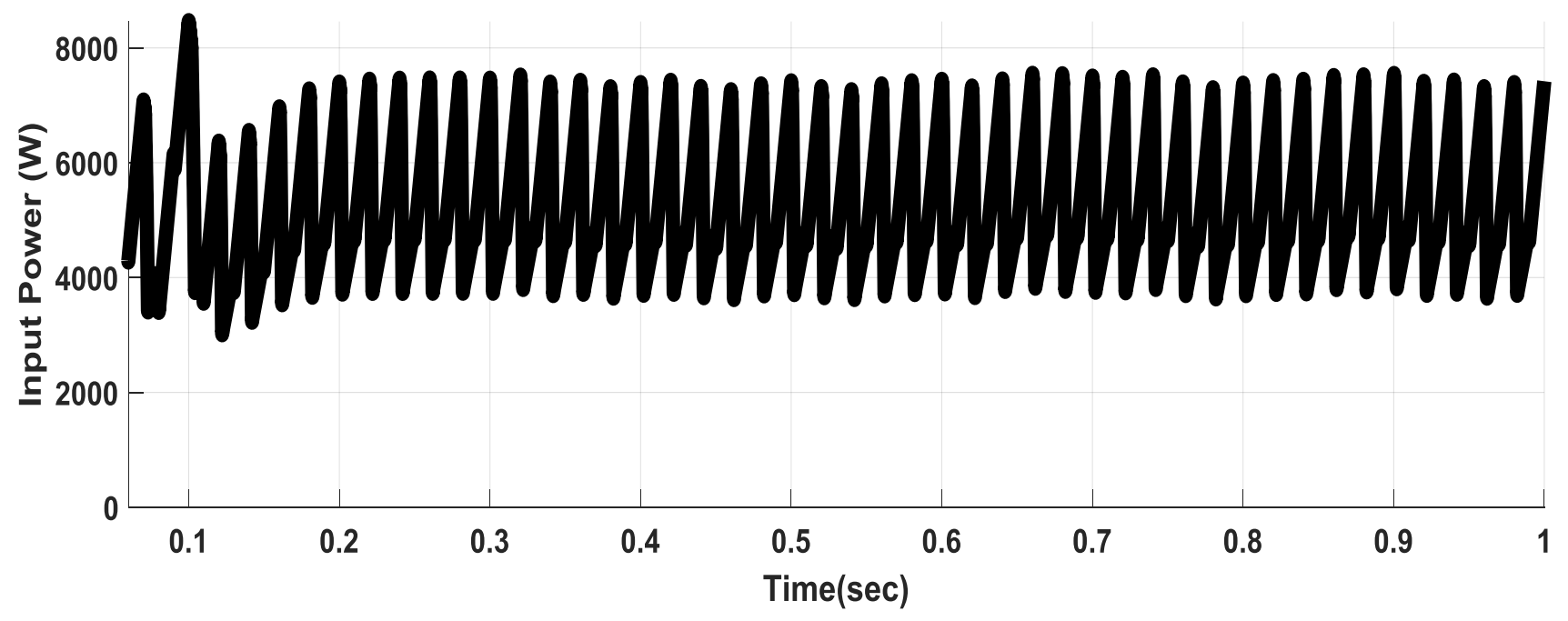

Fig. 8. Input power versus time. 
The input power waveform obtained is presented in Fig. 8. The power waveform relatively mimicked the behavior of the boosted waveform with little exception on the dynamic time response. The average input power according to Fig. 8 is 5800W.The proposed inverter output voltage and current waveforms are shown in Fig. 9. At $0<t<$ $0.02 s$, the AC voltage and current transiently increased from 0 until it stabilized at $338.89 \mathrm{~V}$ and 33.89A. This implies that the steady state or stability is reached at an early point in this type of inverter system. Furthermore, it is observed that the current and voltage time responses of the output inverter current and voltage varies due to the action of IXYSFII 40-06D during the conversion of DC power to AC power. Secondly, it has a pure sine wave with little distortions unlike the conventional ones.

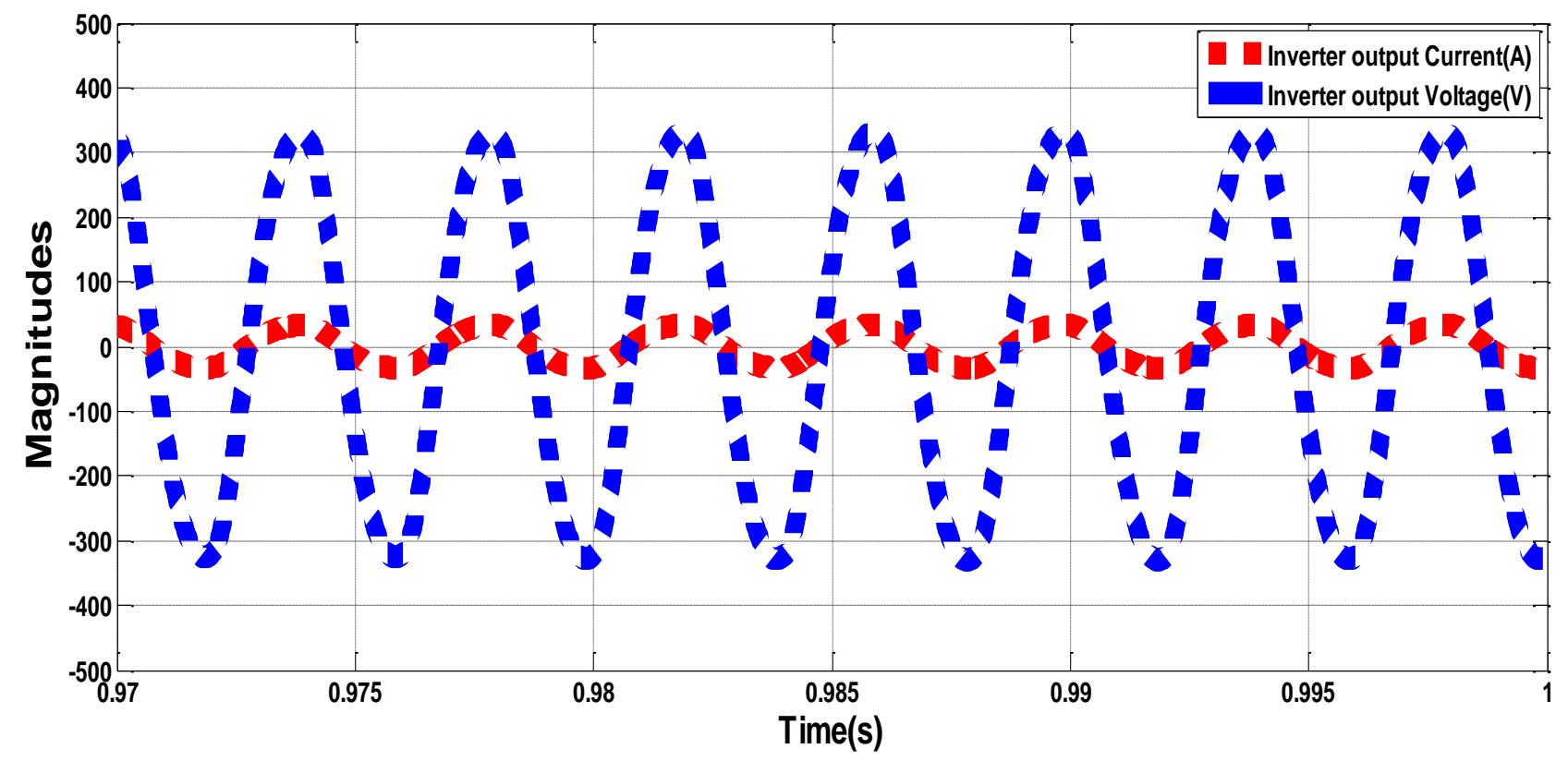

Fig. 9. DC-AC converter output voltage and current waveforms. 
The spectral characteristic of the proposed system is shown in Fig. 10. The results show that the AC output voltage reaches its peak at $338.89 \mathrm{~V}$ and has a THD of $4.294 \%$ at a fundamental frequency of $50 \mathrm{~Hz}$. The results indicate that the system achieves a small power loss, is efficient and has as a THD of $4.294 \%$ which is in the acceptable range of IEEE standards. The results in Fig. 10(a) shows that a wider range of time intervals of $0<t<5 s$ is obtained for the output voltage.
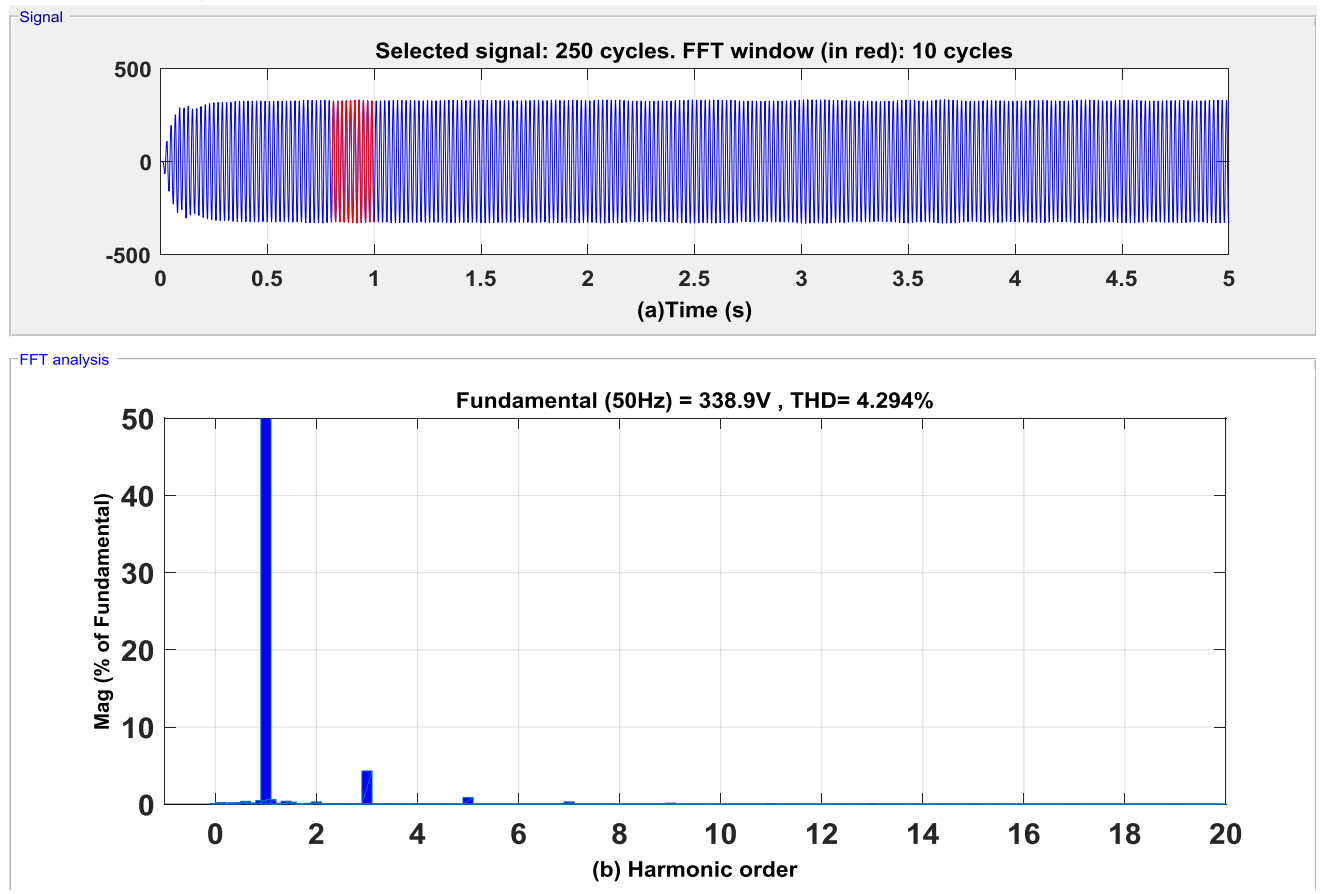

Fig. 10. Spectral output voltage characteristics of inverter.

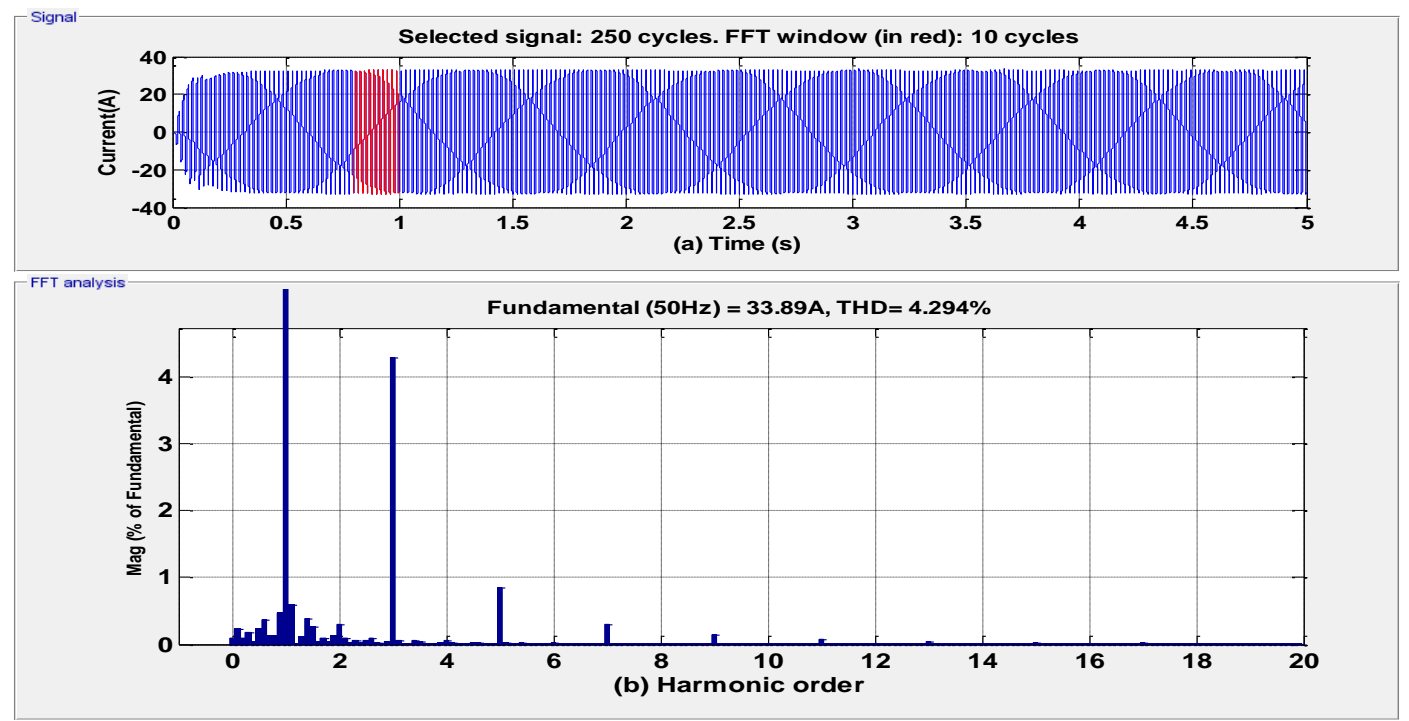

Fig. 11. Spectral output current characteristics of inverter. 
In Fig. 11(a)-(b), we show the result of the output current characteristics. Similar results were achieved in Fig. 10 except for the amplitude of current which is 33.89A.

The power output waveform of the proposed system is shown in Fig. 12. From the power plot against time, it can be observed that the average power output of the proposed system is $5740 \mathrm{~W}$. When $5740 \mathrm{~W}$ is subtracted from the power input of the system, $5800 \mathrm{~W}$, the difference is $60 \mathrm{~W}$. This $60 \mathrm{~W}$ is the power loss of the system.

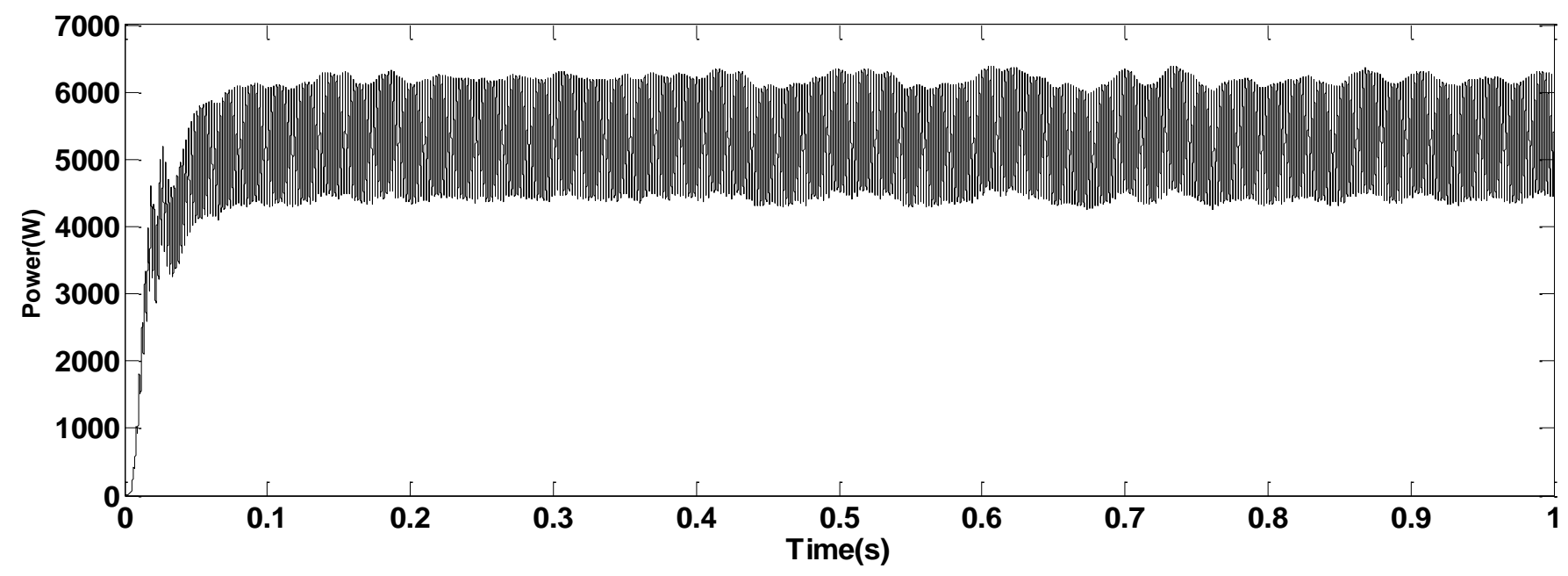

Fig. 12. Power output of the proposed system versus time. 
Fig. 13 presents the statistical analysis of the characteristics of the outputs of the proposed inverter system. Fig. 13(a) shows the histogram plot which can be used to indicate the transient and steady states of the load current. Along the current axis, at a current range of $0<I_{\text {inv }} \leq+27 A$ and $0>I_{\text {inv }} \geq$ $-27 A$ shows a dynamic state of current, while at $+27 A<I_{\text {inv }} \leq+33.89 A$ and $-27 A<$ $I_{\text {inv }} \leq-33.89 A$ indicates the stable region of the current. The spherical plot of current show that as the spherical lines spread (rarefaction) as they leave zero indicating an unstable state but is compressed at the current range of $+27 A<I_{\text {inv }} \leq+33.89 A$ and $-27 A<$ $I_{\text {inv }} \leq-33.89 A$ under the stable state. Fig. 13(c) and Fig. 13(d) represent the spherical and histogram plots of the output voltage of the inverter which is also mimicked in Fig. 13(a) and Fig. 13(b) but differ on the range of numbers based on the dynamic and steady state characteristics of the proposed system.
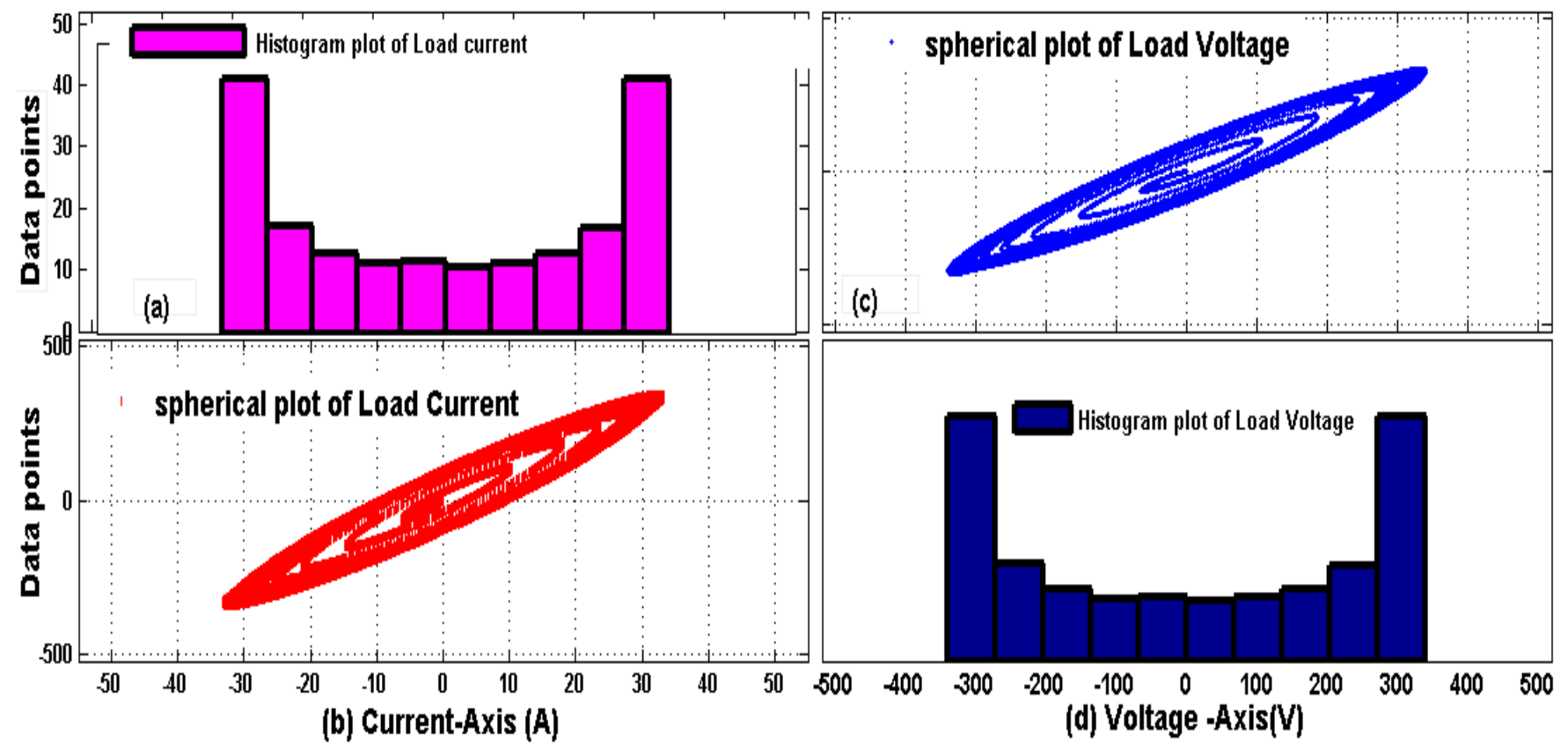

Fig. 13. Statistical analysis of the characteristics of output the proposed inverter. 


\section{(B) EXPERIMENTAL RESULTS AND DISCUSSION}

The results for the dc input voltage waveform is shown in Fig. 14. From the oscilloscopic display, it was observed that the source voltage is $48 \mathrm{~V}$.

The DC-DC boosted voltage represented by Eq. (12) is shown in Fig. 15. The level of the boosted voltage is $450 \mathrm{VDC}$.

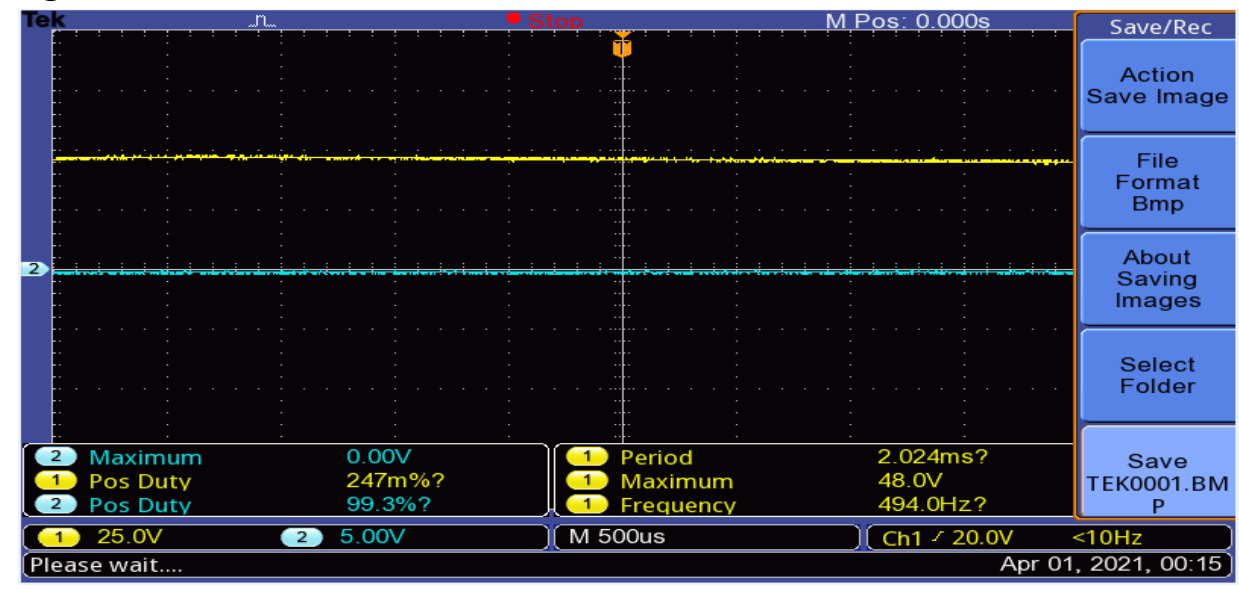

Fig. 14. DC source voltage.

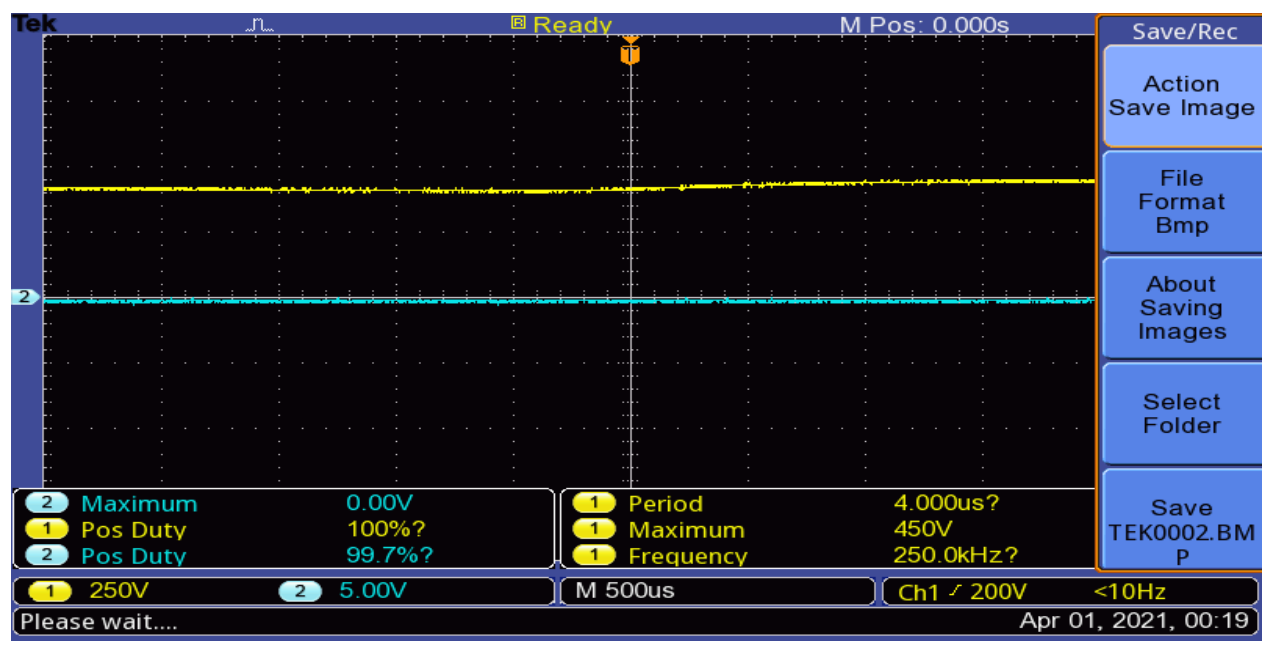

Fig. 15. DC-DC boosted Voltage. 


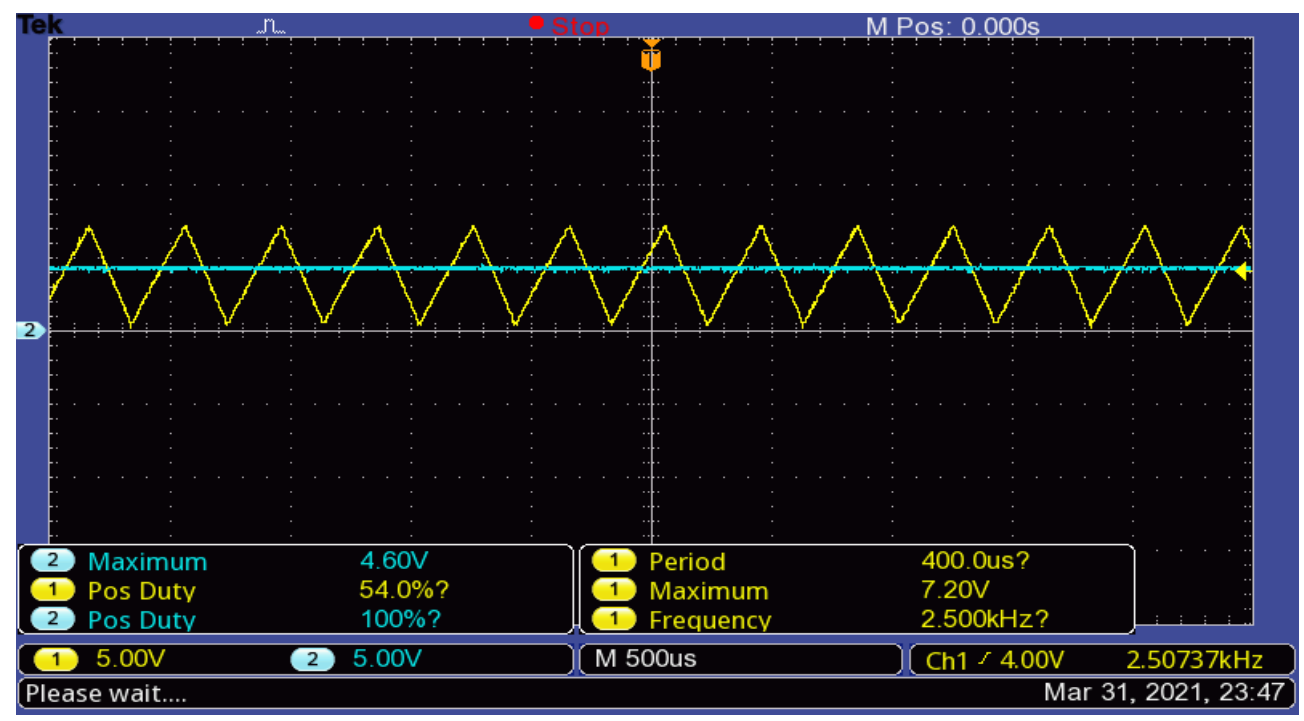

Fig. 16. DC-triangular wave modulation scheme.

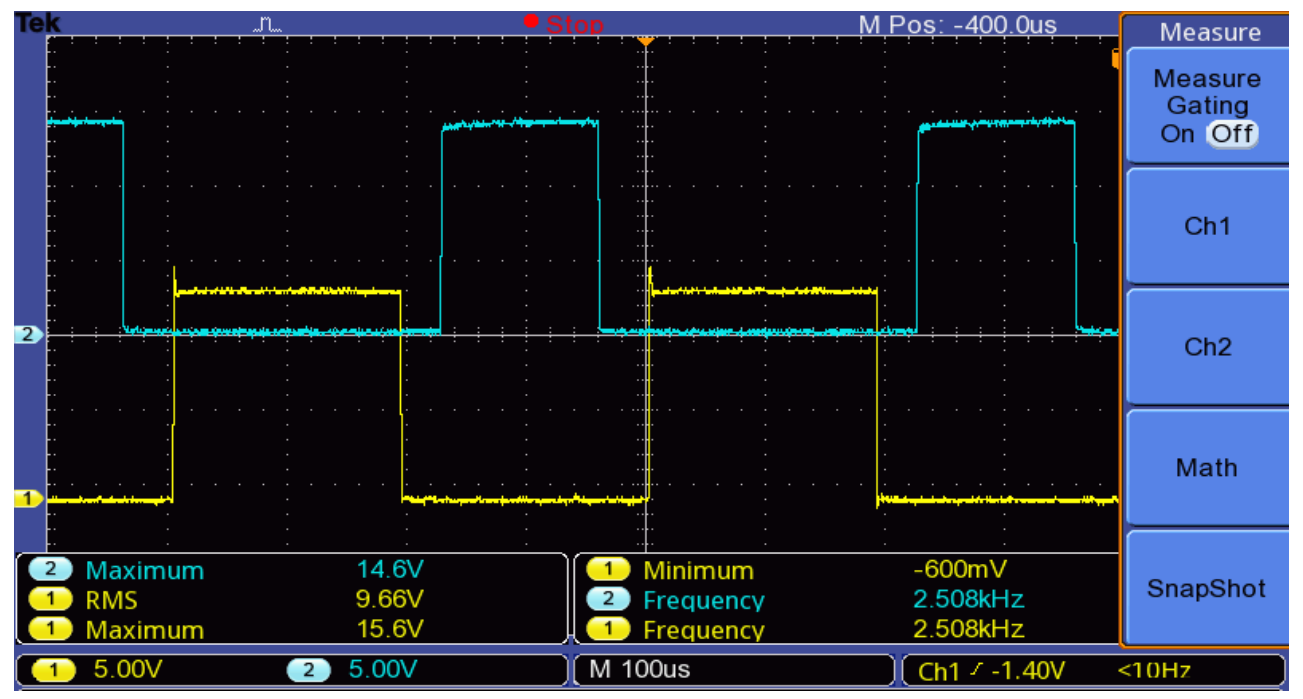

Fig. 17. $\mathrm{S}_{\mathrm{a}}$ and $\mathrm{S}_{\mathrm{b}}$ switching pulses.

The sinusoidal pulse width modulation for the proposed system is shown in Fig. 18. It was observed that the carrier wave has a frequency of $1.077 \mathrm{kHz}$ and a maximum voltage of $8.40 \mathrm{~V}$ whereas the modulating reference signal has a peak voltage of $7.40 \mathrm{~V}$. This ensured that the over modulation was completely prevented. The modulating and carrier wave shown in Fig. 18 were represented mathematically in Eqs. 16 and 18. After comparison with the aid of TL 084, and passing them through 4049, 4081, 4050 CMOS ICs and driver circuits, the switching signals in Fig. 19 is produced. 


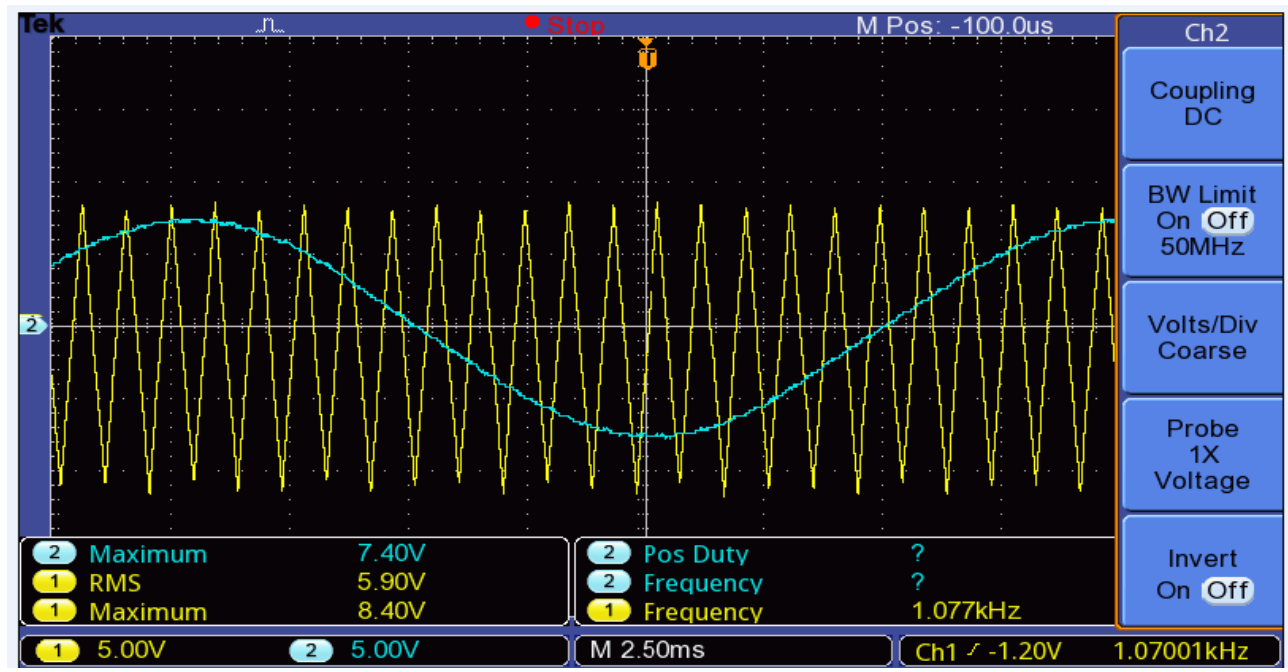

Fig. 18. Sinusoidal pulse width modulation scheme.

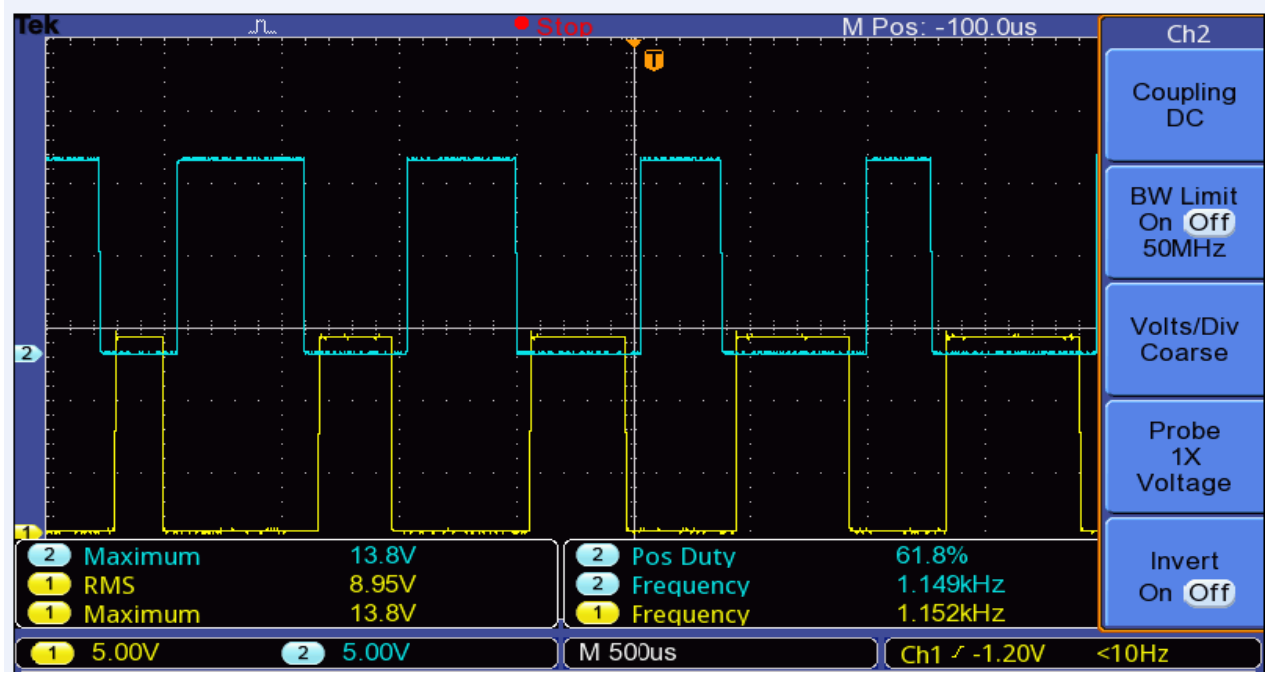

Fig. 19. Switching signals of the first leg of the H-bridge inverter of the proposed system.

Fig. 20 was produced when the expression in Eq. (17) was compared with Eq. (18) and their output signals were passed through the processing circuits. The signals produced in Fig. 20 were used to trigger the second leg of the H-bridge inverter of the proposed system. 


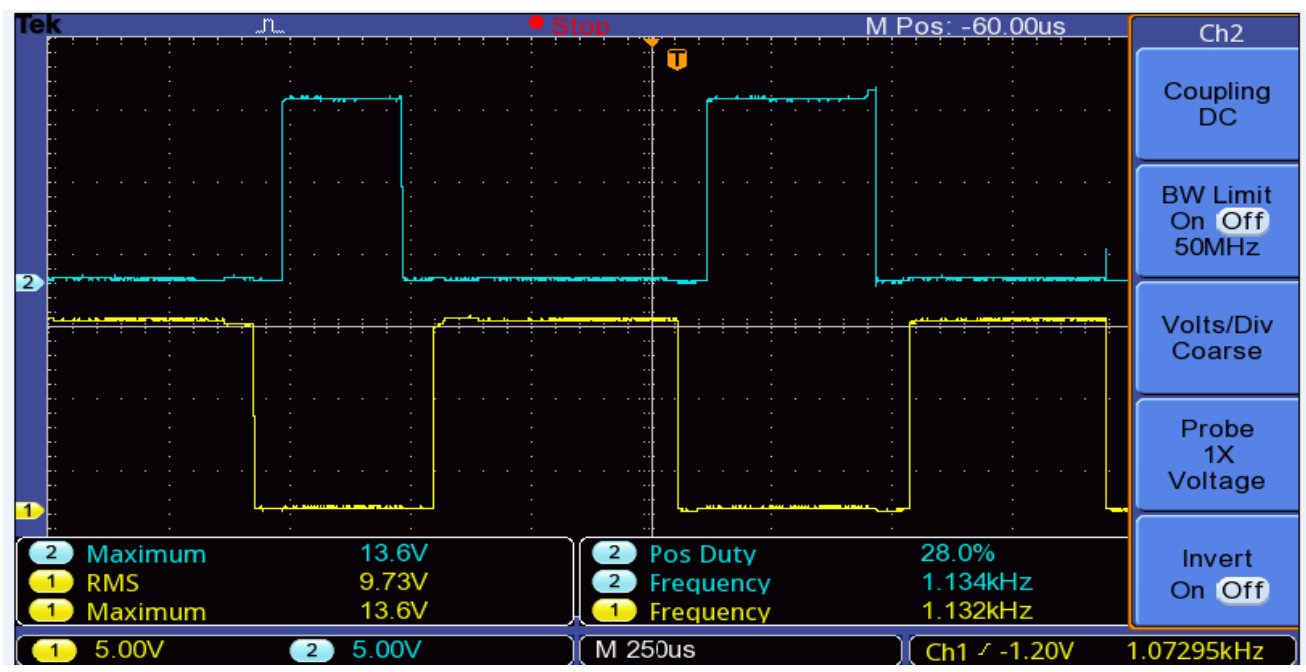

Fig. 20. Triggering signals for second leg of H-bridge inverter of the proposed system.

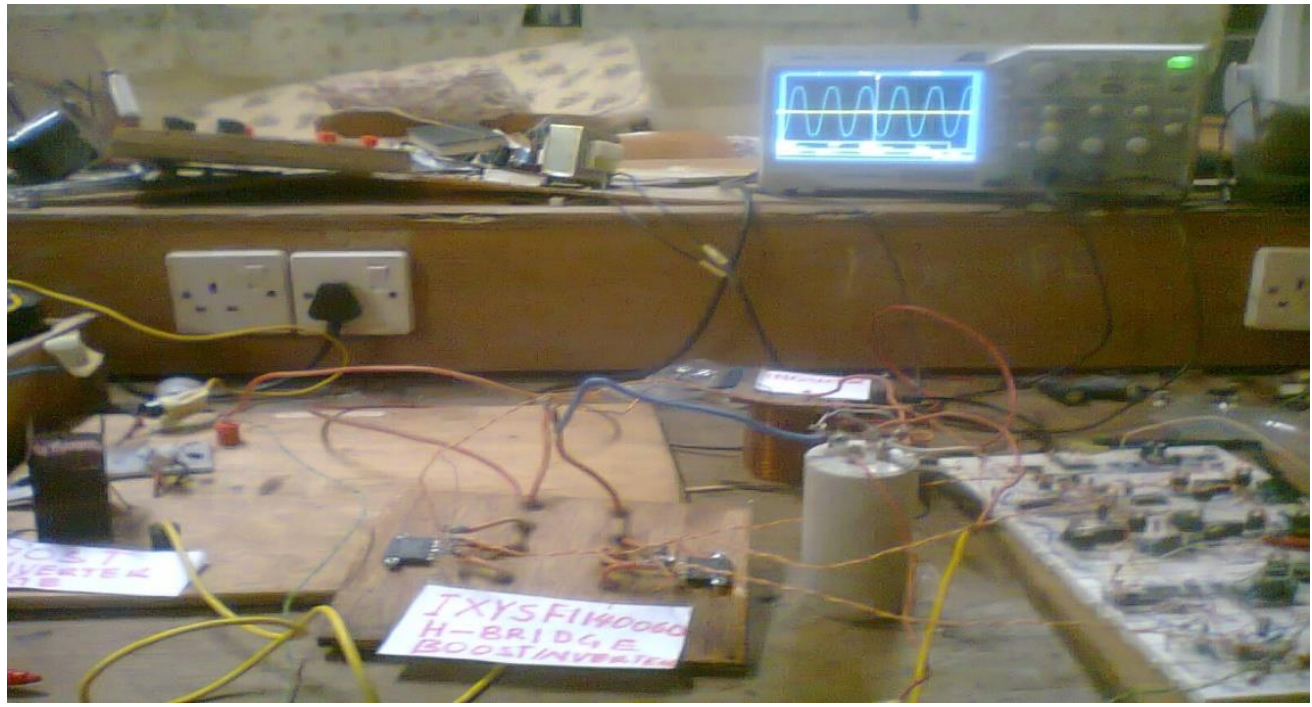

Fig. 21. Prototype of high performance DC-AC converter using snubberless h-bridge power switches with a stressless DC-DC converter.

The complete prototype of the high performance direct current-to-alternating current converter using snubberless h-bridge power switches with an improved DC-DC converter with oscilloscopic display of pure sine wave is shown in Fig. 21. Some useful studies and applications can be found in [26], [27], [28].

\section{CONCLUSION}

A high performance DC-to-AC converter using snubberless $\mathrm{H}$-bridge power switches and an improved DC-DC converter has been analyzed, modeled, simulated in MatLab/Simulink environment, and implemented. achieve our aim, we used reduced sizes of $\mathrm{H}$-bridge inverter power switches with a less stressful DC-DC power 
converter. The results show that the statistical histograms and spherical plots obtained can be graphically used to analyze the dynamics and steady state condition of the inverter output system. Further results indicated that the developed system is highly efficient and reliable, giving an efficiency of $98.9 \%$ with a fast dynamic response and power loss of $60 \mathrm{~W}$.

\section{REFERENCES}

[1] M. H. Rashid. Power Electronics Hand book. $3^{\text {rd }}$ Ed. Butterworth-Heinemann, 30 Corporate Drive, suite 400. Burlington, MA 01803, USA, 2011.

[2] M. U. Agu, Principles of Power Electronics Circuits, UNN Press, Nigeria, 2019.

[3] G. C. Diyoke and C. U. Eya. Modeling and Simulation of Five-Phase Induction Motor Fed With Pulse Width Modulated Five-Phase Multilevel Voltage Source Inverter Topologies,' Journal of Advances in Electrical Devices Volume 4 Issue 2, pp. 6-22, 2019

[4] B. Jyothi, M. V. G. Rao, T. Karthik. Modelling and Simulation of Five Phase Induction Motor Fed with Five Phase Inverter Topologies. Indian Journal of Science and Technology, vol. 8, no. 19, pp. 1- 8, 2015.

[5] G. C. Jiang, X. Li, Y. Chen, and J. Liu. A dc-link voltage self-balanced method for a diode-clamped modular multilevel converter with minimum number of voltage sensors. IEEE Transaction. Power Electron, vol. 28, no. 5, pp. 2125-2139, 2013. DOI: 10.1109/TPEL.2012.2212915.

[6] C.U. Eya, O. Crescent, J. M. Ukwejeh. Solar-powered five level output voltage of dc-to-ac converter using simplified capacitor voltage controlled scheme (SCVCS). IEEE PES/IAS PowerAfrica, Abuja, Nigeria, pp. 1-6, 2019.

DOI:
10.1109/PowerAfrica46609.2019.9078 670

[7] A. O. Salau, C. U. Eya, O. C. Onyebuchi. Nonzero staircase modulation scheme for switching DCDC boost converter. Journal of Control Science and Engineering, vol. 2020, 8347462, pp. 1-15, 2020. DOI: $10.1155 / 2020 / 8347462$.

[8] R. Akhit. A new Technique of PWM boost inverter for solar home application. BRAC University Journal, vol. 4, issues 1, pp. 39-45, 2007.

[9] S. Rajendran and S. S. Kumer. A solar power generation for single phase DC$\mathrm{AC}$ inverter with non-linear variable structure control. Sci. Bull, vol. 76, issue 4, 2014.

[10] R. Akhter and A. Hoque. Analysis of a PWM Boost inverter for solar home application. World Academy of Science, Engineering and Technology, PWASET, vol. 17, pp. 793-797, 2006.

[11] G. R Zhu, S.C Tan, Y.chen and C.K Tse. Mitigation of Low frequency current ripple in fuel-cell inverter systems through waveform control. IEEE Transaction, Power Electronics, vol. 28, no. 2, pp. 779-792, 2013.

[12] C. U. Eya, A. O. Salau, S. E. Oti. Uninterruptible DC-powered boost differential inverter with a Sensorless Changeover System. WSEAS Transactions on Circuits and Systems, vol. 20, pp. 10-26, 2021. DOI: 10.37394/23201.2021.20.2

[13] C. U. Eya and M. U. Agu. Solar-based Boost differential single phase inverter. Nigeria Journal of Technology, vol. 34., no. 1, pp. 164-176, 2015.

[14] B. Wu, et al. A New hybrid boosting converters for renewable energy applications. IEEE Transaction on Power Electronics, vol. 31, no. 2, pp. 1203-1215, 2016. 
[15] B. P. Baddigadiga and M. Ferdowsi. A high voltage gain DC-DC converter based on Modified Dickson Charger Pump Voltage Multiplier. IEEE Transaction on Power Electronics, vol. 32, no. 10, pp. $7707-7715,2017$.

[16] F. Gao, D. Li, P. C. Loh, Y. Tang, and P. Wang. Indirect dc link voltage control of two stage single phase PV Inverter. Energy conversion Congress and Exposition, pp. 1166-1172, 2009.

[17] F. He, Z. Zhao, L. Yaun and S. Lu. A DC-link voltage control scheme for single phase grid-connected PV Inverters Energy conversion Congress and Exposition, pp. 3941-3945, 2011.

[18] S. H. Lee, T. P. An, and H. Cha. Mitigation of Low frequency Ac ripple in single-phase photovoltaic power conditioning. Journal of Power electronics, vol. 10, pp. 1-7, 2006.

[19] C. U. Eya. Practical implementation of an improved standby boost uninterruptible power supply, vol. 3, pp. 1-7, 2014.

[20] S. Poshtkouhi, A. Biswas and O. Trescases. DC-DC converter for high granularity, sub-string MPPT in Photovoltaic applications using a virtual parallel connection. Proc. IEEE 27th Annu. Appl. Power Electron. Conf. Expo., pp. 86-92, 2012.

[21] M. Forouzesh, Y. Siwakoti, Saman A. Gorji, F. Blaabjerg, and B. Lehman. Step-Up DC-DC Converters: A Comprehensive Review of VoltageBoosting Techniques, Topologies, and Applications. IEEE Transactions on Power Electronics, vol. 32, no. 12, pp. 9143-9178, 2017.

[22] T. M. Aiswarya and M. Prabhakar. An efficient High Gain DC-DC Converter for Automotive Applications. International Journal of Power Electronicsm, vol. 6, pp. 242-252, 2015.
B. E. Elnaghi, M. E. Dessouki, M. N. Abd-Alwahab and E. Eikholy. Development of two stage Converter for single-phase Inverter without Transformer for PV systems, vol. 9, pp. 101-111, 2019.

www.data sheet of IXYS ISOPLUS FII 40-06D.com, 2011

T. L. Skvarenina. The power Electronics Handbook Industrial Electronics Series. CRC Press, Library of Congress Cataloging-in-Publication, 2002.

[26] Nur Aqilah Othman, Hamzah Ahmad, The Analysis of Covariance Matrix for Kalman Filter based SLAM with Intermittent Measurement, Int. J. of Applied Mathematics, Computational Science and Systems Engineering, pp.66-70, Volume 1, 2019

[27] S.Sivaperumal, V. Sundarapandian, "Hybrid Synchronization of Hyperchaotic Qi Systems via Sliding Mode Control", Int. J. of Applied Mathematics, Computational Science and Systems Engineering, pp.71-75, Volume 1, 2019.

[28] Rashed Bahrekazemi, Alireza Jalilian, "Assessment of Different Compensation Strategies in Hybrid Active Power Filters", Int. J. of Applied Mathematics, Computational Science and Systems Engineering, pp.19-24, Volume 2, 2020.

\section{Creative Commons Attribution License 4.0 (Attribution 4.0 International, CC BY 4.0)}

This article is published under the terms of the Creative Commons Attribution License 4.0

https://creativecommons.org/licenses/by/4.0/deed.en_US 